\title{
Thelma Jurgrau, George Sand's Use of Christian Imagery in Four Works Depicting Jewish Characters
}

\section{Morena Petrich}

\section{(2) OpenEdition}

1 Journals

\section{Edizione digitale}

URL: http://journals.openedition.org/studifrancesi/27787

DOI: 10.4000/studifrancesi.27787

ISSN: 2421-5856

\section{Editore}

Rosenberg \& Sellier

\section{Edizione cartacea}

Data di pubblicazione: 31 décembre 2006

Paginazione: 622

ISSN: 0039-2944

\section{Notizia bibliografica digitale}

Morena Petrich, «Thelma Jurgrau, George Sand"s Use of Christian Imagery in Four Works Depicting

Jewish Characters », Studi Francesi [Online], 150 (L | III) | 2006, online dal 30 novembre 2015, consultato il 08 novembre 2020. URL : http://journals.openedition.org/studifrancesi/27787 ; DOI : https://doi.org/ 10.4000/studifrancesi.27787

Questo documento è stato generato automaticamente il 8 novembre 2020.

\section{(c) $(1)$}

Studi Francesi è distribuita con Licenza Creative Commons Attribuzione - Non commerciale - Non opere derivate 4.0 Internazionale. 


\title{
Thelma Jurgrau, George Sand's Use of Christian Imagery in Four Works Depicting Jewish Characters
}

\author{
Morena Petrich
}

\section{NOTIZIA}

THELMA JURGRAU, George Sand's Use of Christian Imagery in Four Works Depicting Jewish Characters, George Sand Studies, Vol. 24, 2005, pp. 3-23.

1 Thelma Jurgrau affronta il pensiero, con le zone d'ombra e di ristagno, della paladina delle idee progressiste di mezzo secolo di storia (sociale, politica e letteraria) francese del XIX secolo sugli ebrei. Non è un mistero che il tenace ottimismo di Sand ha intravisto nell'ispirazione ai precetti cristiani una via di fuga e di salvezza dalle aspre delusioni che le aveva riservato l'esperienza politica: il suo noto umanitarismo filantropico si presta perfettamente ad una lettura in filigrana di quattro sue opere alla ricerca di tracce rivelatrici del suo atteggiamento e, al contempo, sintomi, letterari e simbolici dell'opinione pubblica nazionale a lei contemporanea. I testi presi in esami sono: i romanzi Spiridion (1838), Valvèdre (1861), Monsieur Sylvestre (1865) e il dramma Les Mississipiens (1840). Non è un mistero che le posizioni ideologiche di Sand devono molto a Pierre Leroux che faceva confluire nelle sue teorie fede cristiana e fiducia nel progresso sociale. Mantenendo in primo piano il parallelo tra storia nazionale ed individuale e quindi evidenziando le ripercussioni degli eventi storico-politici nella dimensione personale dell'autrice, è interessante notare come, in seguito all'inasprirsi dell'ostilità nei confronti degli ebrei, che crebbe in particolare durante l'acme rivoluzionaria del 1848 e che si manifestò in episodi di esacerbata intolleranza e violenza anti-ebraica (come quelli avvenuti in Alsazia), nell'epistolario di Sand, compaiano segni di razzismo. Analizzando i tratti salienti e secondari dei personaggi ebrei che figurano nelle già citate opere, l'A. evidenzia lo svolgersi dei sentimenti e delle opinioni di Sand a proposito del Giudaismo in Francia che, pur evolvendo verso 
una sempre crescente focalizzazione sul singolo individuo - con le sue caratteristiche individuali che poco, se non nulla, hanno a che vedere con la sua appartenenza etnica (oggi; razziale allora) -, finisce per soccombere, sopraffatto dall'insormontabile potere dell'immaginario simbolico. 